\title{
Characterization and oxygen binding properties of des-Arg human hemoglobin
}

\author{
P. Tosqui ${ }^{1}$, C.R. Bonini-Domingos ${ }^{2}$ and M.F. Colombo ${ }^{1}$ \\ 1Departamento de Física, ${ }^{2}$ Departamento de Biologia, Instituto de Biociências, Letras e Ciências Exatas, \\ Universidade Estadual Paulista, São José do Rio Preto, SP, Brasil
}

Correspondence to: P. Tosqui, Departamento de Física, Instituto de Biociências, Letras e Ciências

Exatas, UNESP, 15054-000 São José do Rio Preto, SP, Brasil

E-mail: pritosqui@gmail.com

\begin{abstract}
The role of chloride in the stabilization of the deoxy conformation of hemoglobin $(\mathrm{Hb})$, the low oxygen affinity state, has been studied in order to identify the nature of this binding. Previous studies have shown that arginines $141 \alpha$ could be involved in the binding of this ion to the protein. Thus, des-Arg Hb, human hemoglobin modified by removal of the $\alpha$-chain $\mathrm{C}$-terminal residue Arg $141 \alpha$, is a possible model for studies of these interactions. The loss of Arg $141 \alpha$ and all the salt bridges in which it participates is associated with subtle structural perturbations of the $\alpha$-chains, which include an increase in the conformational flexibility and further shift to the oxy state, increasing oxygen affinity. Thus, this $\mathrm{Hb}$ has been the target of many studies of structural and functional behavior along with medical applications. In the present study, we describe the biochemical characterization of desArg $\mathrm{Hb}$ by electrophoresis, high-performance liquid chromatography and mass spectroscopy. The effects of chloride binding on the oxygen affinity and on the cooperativity to des-Arg $\mathrm{Hb}$ and to native human hemoglobin, $\mathrm{HbA}$, were measured and compared. We confirm that des-Arg $\mathrm{Hb}$ presents high oxygen affinity and low cooperativity in the presence of bound chloride and show that the binding of chloride to des-Arg does not change its functional characteristics as observed with $\mathrm{HbA}$. These results indicate that Arg $141 \alpha$ may be involved in the chloride effect on $\mathrm{Hb}$ oxygenation. Moreover, they show that these residues contribute to lower $\mathrm{Hb}$ oxygen affinity to a level compatible with its biological function.
\end{abstract}

Key words: des-Arg hemoglobin; Oxygen affinity

Part of a Master's thesis presented by P. Tosqui to the Graduate Program in Molecular Biophysics, IBILCE, UNESP, São José do Rio Preto, SP, Brazil.

Research supported by CNPq and FAPESP.

Received September 3, 2008. Accepted March 16, 2009

\section{Introduction}

Hemoglobin $(\mathrm{Hb})$ is an allosteric protein found mainly in red cells whose main function is to deliver oxygen from the lungs to the tissues. Hbs are tetrameric and are composed by two $\alpha$-chains and two $\beta$-chains, each containing a heme group to which a single oxygen molecule binds reversibly (1). To perform its function, $\mathrm{Hb}$ assumes different structural conformations with distinct $\mathrm{O}_{2}$ affinities. The shift between these states is regulated by the presence of allosteric effectors such as organic phosphates and monovalent anions. These anions preferentially bind to the deoxy form (T-state), increasing the stability of the low- affinity T-state compared to the high-affinity R-state, thus increasing $p_{50}$, the $\mathrm{O}_{2}$ pressure at half saturation (2). In human red cells, 2,3-diphosphoglycerate is the main allosteric effector of hemoglobin $A(\mathrm{HbA})$, whose binding has been very well described in the literature. This phosphate has high affinity for $\mathrm{HbA}$, with binding occurring at a very specific site that consists of eight cationic residues located in the central cavity of the protein (3). However, it has been shown that $\mathrm{HbA}$ also binds monovalent anions that also stabilize the deoxy form, reducing its affinity for $\mathrm{O}_{2}$. The most abundant of these physiological ions is the chloride ion (4).

The nature of the chloride modulation of $\mathrm{Hb}$ affinity for 
$\mathrm{O}_{2}$ has been the object of many studies in the past years, but no consensus has been reached about how this binding occurs. First it was suggested that this binding would involve specific sites, i.e., the N-terminal Val $1 \beta 2$ and the guanidine group of Arg 141 $\alpha 1$, the C-terminal residue (57). In other studies, Perutz et al. (8) proposed that the binding of chloride to $\mathrm{Hb}$ is not specific but is due to the opening of the central cavity during the T-R transition, in which the positively charged amino acids would attract the anions. In more recent studies, Fronticelli et al. (9), comparing human and bovine $\mathrm{Hb}$, again identified specific chloride binding sites, justifying their findings about the different affinities of the two Hbs for oxygen (9-11).

In 1999, Hui et al. (12) proposed Arg141 $\alpha 1$ and Arg $141 \alpha 2$ as the chloride binding sites based on the comparison of crystallographic structure maps of deoxy $\mathrm{HbA}$ and chemically modified Hbs. Crystallographic studies carried out by our research group have also identified these arginines as chloride sites. This evidence was obtained by analyzing maps of different electronic densities of deoxy $\mathrm{Hb}$ crystallized in the total absence of anions and in the presence of high chloride concentrations. In the same study, arginines $92 \alpha 1$ and $92 \alpha 2$ were also identified as these possible sites. These four sites follow the chloride binding pattern identified for other proteins (Seixas FAV, Colombo MF, unpublished results).

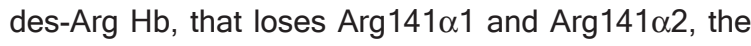
presumed sites of chloride binding, is found in vivo in the placenta, where the carboxypeptidase-M enzyme, present in the microvillous syncytiotrophoblast, removes the arginine residues (13).

These residues play an important role in stabilizing the T structure by interaction with other amino acids. Arginine $141 \alpha$ forms salt bridges with Lys $127 \alpha 2$, Asp $126 \alpha 2$, and Val $\alpha 2(14,15)$, with a consequent increase in molecule flexibility that shifts the equilibrium to the high-affinity structure $\mathrm{R}$ and reduces the cooperativity value indicated by the Hill coefficient. Despite this structural alteration, there is no modification in the heme group region and the Tyr $140 \alpha$ residue is positioned in the same direction as in $\mathrm{HbA}$ (16). Because of these functional changes, des-Arg $\mathrm{Hb}$ has been used in vasoconstrictive studies and in the development of blood substitutes (17).

The connection of this structural and functional behavior in $\mathrm{Hbs}$, possibly modulated by chloride binding, has led us to study the biochemical and functional properties of des-Arg $\mathrm{Hb}$. One approach to the elucidation of this matter is to perform comparative studies of human $\mathrm{Hb}$ and chemically modified des-Arg $\mathrm{Hb}$, obtained by the carboxypeptidase-B (CPB) hydrolysis, which specifically removes the $141 \alpha 1$ and $141 \alpha 2$ arginine residues (18).

\section{Material and Methods}

A blood sample was collected from a healthy nonsmoking adult male by venipuncture using a heparinized syringe, after obtaining written informed consent. The purification procedure followed the method previously described by Colombo and Bonilla-Rodriguez (19), based on the protocol of Williams and Tsay (20) and was monitored by non-denaturating PAGE. The purified $\mathrm{HbA}$ was extensively deionized by several passages through an Amberlite MB-1 column.

des-Arg $\mathrm{Hb}$ was obtained from $\mathrm{HbA}$ by enzymatic cleavage, as previously described in the literature (21-24). $\mathrm{C}$-terminal residues were removed by the digesting chains with CPB (grade COBC, Worthington, USA) in 20 mM Tris$\mathrm{HCl}$ buffer, $\mathrm{pH} 8.0$, at an enzyme to substrate weight ratio of $1: 100$ at room temperature for approximately $2 \mathrm{~h}$. The modified $\mathrm{Hb}$ was purified by gel filtration through a Sephadex G-25 (PD-10 column, GE Healthcare, USA) equilibrated with $10 \mathrm{mM}$ HEPES-NaOH buffer, $\mathrm{pH} \mathrm{6.9}$, for the removal of free arginine residues.

Once the arginine residues were removed from the solution, the sample was purified chromatographically on an ion-exchange column using DEAE A50 Sephadex, equilibrated with $10 \mathrm{mM}$ HEPES-NaOH containing $0.1 \mathrm{M}$ $\mathrm{NaCl}$ buffer, $\mathrm{pH} 7$, for separation of des-Arg $\mathrm{Hb}$ from the $\mathrm{CPB}$, on the basis of their isoelectric points: $(\mathrm{pl}=7.1$ for $\mathrm{Hb}$ vs $\mathrm{pl}=6.0$ for $\mathrm{CPB})(25,26)$. $\mathrm{HbA}$ and des-Arg $\mathrm{Hb}$ were concentrated using Amycon concentrators and stored in liquid nitrogen until use.

The efficiency of the CPB hydrolysis was checked by ESI-Q-TOF mass spectrometry using a Q-TOF Micro apparatus equipped with an electrospray ionization source operated in the positive or negative ion mode. Samples were diluted in $50 \%$ acetonitrile, $0.1 \%$ trifluoroacetic acid in ultrapure water and applied to the equipment using a syringe pump at a flow rate of $5 \mu \mathrm{L} / \mathrm{min}$. This procedure permits comparison of the molecular mass of $\mathrm{Hb}$ and the products. The difference in mass can be used to identify amino acids released by CPB treatment.

des-Arg $\mathrm{Hb}$ was characterized by electrophoretic methods and chromatography.

\section{Isoelectric focusing}

$\mathrm{HbA}$ and des-Arg $\mathrm{Hb}$ samples were analyzed by isoelectric focusing on agarose gel in the presence of the ampholytes, forming a linear $\mathrm{pH}$ gradient. The gel was positioned in a horizontal direction and placed on a cool platform. Electrolyte strips saturated with $1 \mathrm{M}$ phosphoric acid and $1 \mathrm{M}$ sodium hydroxide were placed at the anode and cathode extremes of the gel, respectively. The plati- 
num electrode connected to the gel maintains the gel in contact with the electronic apparatus. The samples were applied to the center of the gel and subjected to an electrical field of $8 \mathrm{~A}$, with a cathode and an anode pole at each extreme of the gel.

\section{Electrophoretic methods}

The $\mathrm{HbA}$ and des-Arg $\mathrm{Hb}$ samples were characterized by electrophoresis at alkaline $\mathrm{pH}$ on cellulose acetate with Tris-EDTA-boric acid (TEB) buffer at $\mathrm{pH} 8.6$, and at acidic $\mathrm{pH}$ on agar gels (Oxoid, UK) with phosphate buffer at $\mathrm{pH}$ 6.2, as described by Bonini-Domingos (27).

\section{Globin chain analysis}

The $\alpha$ - and $\beta$-globin chains were separated by the urea-2 mercaptoethanol method and analyzed by electrophoresis in TEB at alkaline $\mathrm{pH} 8.6$ on acetate cellulose according to the method described by Schneider (28). Acidic $\mathrm{pH}$ electrophoresis was carried out on cellulose acetate at $\mathrm{pH} 8.7$ in TEB-urea-2 mercaptoethanol buffer and on a $12 \%$ polyacrylamide gel with $5 \%$ acetic acid buffer. When the electrophoresis was completed, amido black on Coomassie blue staining was used to detect protein, followed by destaining with $7 \%$ acetic acid and $30 \%$ methanol solution (29).

\section{High-performance liquid chromatography}

$\mathrm{Hb}$ and des-Arg $\mathrm{Hb}$ were separated on the basis of their ionic interactions with the cationic column by elution with two sodium phosphate buffers to form a $\mathrm{pH}$ gradient of increasing ionic strength. The apparatus contains $3 \times 0.46-$ $\mathrm{cm}$ nonporous cation exchange resin, which was eluted at $2 \mathrm{~mL} / \mathrm{min}$ (30). The elution profile of the column was standardized for quantitative screening of $\mathrm{Hb}$ variants using the heterozygote $\beta$ thalassemia kit (BioRad, USA), containing the $\mathrm{Hbs} \mathrm{A} 2 / \mathrm{F}$ patterns, which allows the quantification of $\mathrm{Hb} \mathrm{A} 2, \mathrm{Hb} F, \mathrm{Hb} \mathrm{A}, \mathrm{Hb} \mathrm{S}$, and $\mathrm{Hb}$ C. Protein elution was monitored inline by absorbance measurements at 415 and $690 \mathrm{~nm}$ as a function of time.

\section{Oxygen binding curves}

Oxygen binding experiments were performed with 60 $\mu \mathrm{M}$ (heme) $\mathrm{Hb}$ in $10 \mathrm{mM}$ HEPES-NaOH buffer, $\mathrm{pH}$ 7.2, at room temperature by the tonometric-spectrophotometric method (31). The protein concentrations were estimated using the extinction coefficients reported by Benesch et al. (32). Oxygen binding curves were measured in the presence and in the absence of $100 \mathrm{mM} \mathrm{NaCl}$, and the functional parameters $p_{50}$ and Hill's coefficient $\left(n_{50}\right)$, a measure of cooperativity, were calculated from the Hill Plot by linear regression near half saturation.

\section{Results and Discussion}

$\mathrm{HbA}$ and des-Arg $\mathrm{Hb}$ (prepared from the same $\mathrm{Hb}$ sample) were submitted to mass spectrometry in order to assess the efficiency of arginine release and to determine if the $\mathrm{Hb}$ and its products were homogeneous (Figure 1). The masses of the human $\mathrm{Hb}$ chains are 15126.38 $\mathrm{Da}$ for the $\alpha$-chain and 15867.24 Da for the $\beta$-chain. The masses of the des-Arg $\mathrm{Hb}$ are 14970.74 $\pm 0.16 \mathrm{Da}$ for the $\alpha$-chain and $15867.36 \pm 0.21 \mathrm{Da}$ for the $\beta$-chain. When the mass of the des-Arg $\alpha$-chain is substracted from that of the $\mathrm{HbA} \alpha$ chain, the difference is 155.99 . This corresponds to the mass of one arginine residue, 156.17 per $\alpha$-chain. No significant quantities of other proteins or $\alpha$-chains were detected.
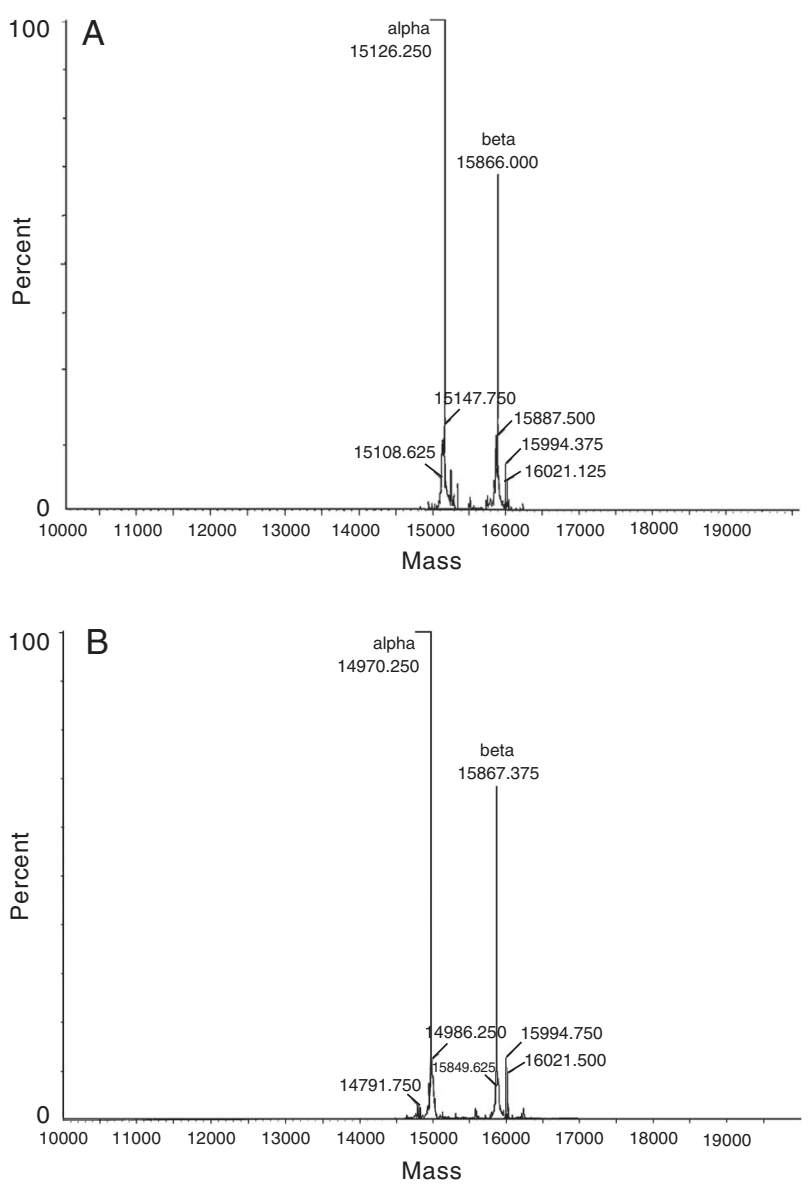

Figure 1. Mass spectrometric analysis of hemoglobin $A(\mathrm{HbA})$, and des-Arg Hb. A, The masses of the $\mathrm{HbA}$ chains are 15126.38 $\mathrm{Da}$ for the $\alpha$-chain and 15867.24 $\mathrm{Da}$ for the $\beta$-chain. $B$, The masses of the des-Arg Hb chains are $14970.74 \pm 0.16$ for the $\alpha$ chain and $15867.36 \pm 0.21$ for the $\beta$-chain. The difference between the $\alpha$-chains is $\sim 156 \mathrm{Da}$, the exact mass of the arginine residue. 
The methods used for the electrophoretic characterization of des-Arg $\mathrm{Hb}$ were those widely used in studies of $\mathrm{Hb}$ variants. The electrophoretic pattern of des-Arg $\mathrm{Hb}$ migration differs from that found for intact $\mathrm{Hb}$. Figure 2 shows the

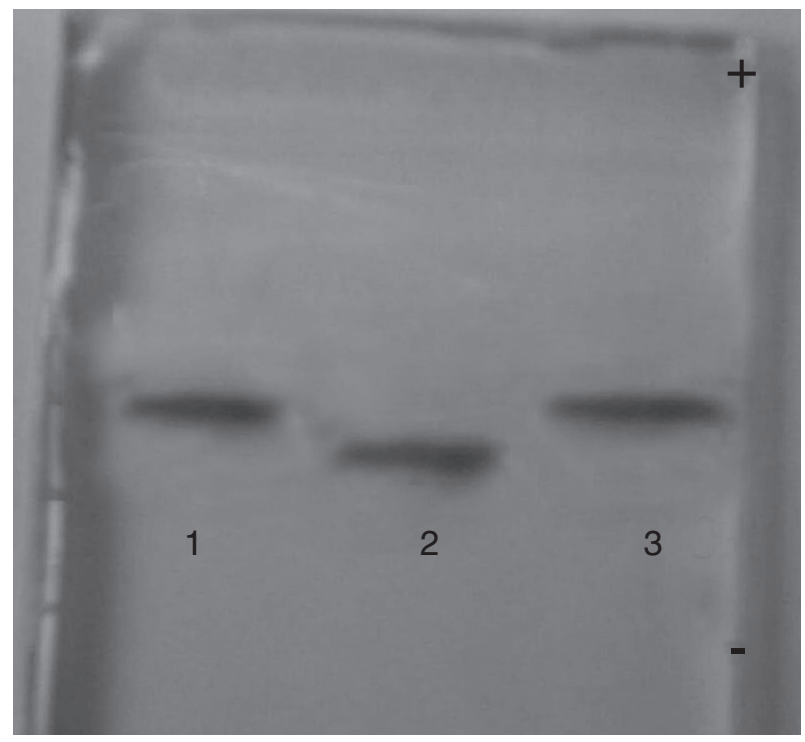

Figure 2. Isoelectric focusing of hemoglobin $A(\mathrm{HbA})$ and desArg $\mathrm{Hb}$. The volume applied for each sample was $10 \mu \mathrm{L}$ of the stock concentrations $7 \mathrm{mM} /$ heme for des-Arg $\mathrm{Hb}$ and $11 \mathrm{mM} /$ heme for $\mathrm{HbA}$. Lanes 1 and 3, des-Arg $\mathrm{Hb}$; lane 2, $\mathrm{HbA} .(+)=$ positive pole and $(-)=$ negative pole. des-Arg $\mathrm{Hb}$ migrated more to the positive pole than $\mathrm{HbA}$ because of the loss of two positively charged arginine residues in each tetramer.

Figure 3. Electrophoresis of hemoglobin on cellulose acetate. Lane 1, $\mathrm{HbA}$; lane 2, des-Arg $\mathrm{Hb}$. A, Phosphate buffer, $\mathrm{pH} 6.2$, stained with Coomassie blue. For each sample, $20 \mu \mathrm{L}$ of stock concentration of $11 \mathrm{mM} /$ heme for $\mathrm{HbA}$ and $7 \mathrm{mM} /$ heme for des-

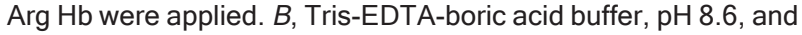
Ponceau stain. For each sample, $15 \mu \mathrm{L}$ of stock concentration of $11 \mathrm{mM} /$ heme for $\mathrm{HbA}$ and $7 \mathrm{mM} /$ heme for des-Arg $\mathrm{Hb}$ were applied. The proteins migrate from the negative (-) to the positive pole $(+)$ and in both cases des-Arg $\mathrm{Hb}$ migrated closer to the positive pole.

results of the isoelectric focusing experiment, which reveal a difference in the migration of the two Hbs. des-Arg $\mathrm{Hb}$ (lanes 1 and 3) migrates more towards the cathode than intact $\mathrm{Hb}$ (lane 2) due to the loss of two positively charged arginine residues.

$\mathrm{Hb}$ electrophoresis on cellulose acetate, using intact $\mathrm{HbA}$ (lane 1) as control and des-Arg $\mathrm{Hb}$ (lane 2) as the analyte, was performed both at acidic $\mathrm{pH}$ (6.2) and alkaline $\mathrm{pH}$ (8.6), as illustrated in Figure 3. The des-Arg Hb sample migrated towards the positive pole under both $\mathrm{pH}$ conditions, reaching a position closer to this cathodic region than the $\mathrm{HbA}$ sample. This fact can be explained as a consequence of the loss of two arginine residues with positive charges, leaving des-Arg $\mathrm{Hb}$ with a more negative charge than $\mathrm{HbA}$.

Figure 4 shows the results of chain electrophoresis at acidic and alkaline $\mathrm{pH}$. The $\alpha$ - and $\beta$-globin chains migrate towards the positive pole. The $\beta$-chains of $\mathrm{HbA}$ and desArg $\mathrm{Hb}$ are identical and therefore their migration profile was the same, whereas the $\alpha$-chains had different patterns. The $\alpha$-chain of des-Arg $\mathrm{Hb}$ migrated closer to the positive polar region than the $\alpha$-chain of $\mathrm{HbA}$ due to the loss of the arginine residues, characterizing specific modification of the charge of the $\alpha$-chain.

The HPLC chromatograms of $\mathrm{Hb}$ and des-Arg $\mathrm{Hb}$ are shown in Figure 5. des-Arg $\mathrm{Hb}$ is eluted at the position of the acetylated subfraction of $\mathrm{HbA}(\mathrm{P} 3)$. Acetylation of $\mathrm{Hb}$ eliminates to positive charges of lysines, residues at neutral $\mathrm{pH}$, which makes the overall charge of the protein more

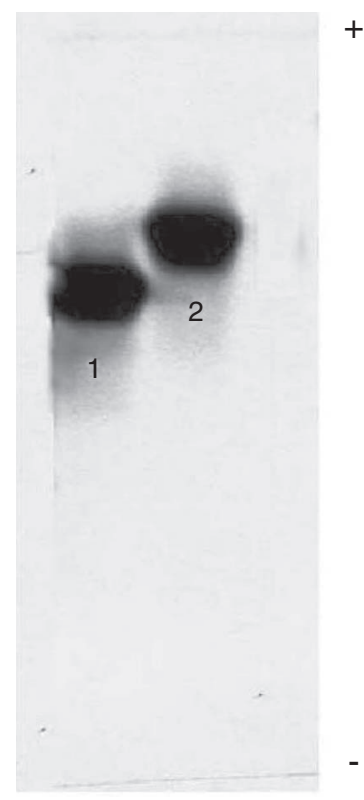

A

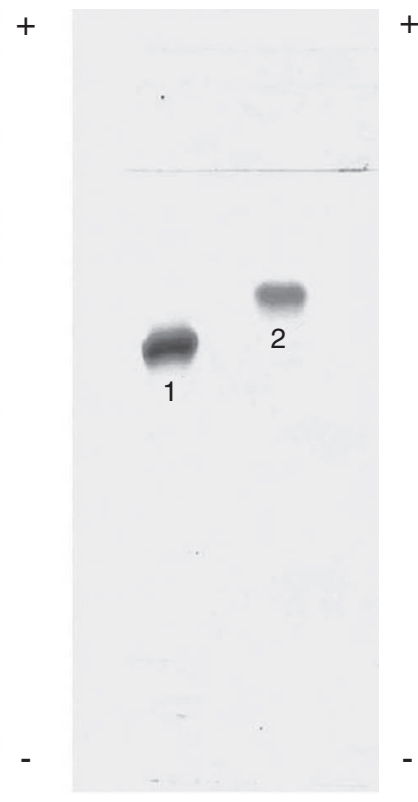

B 
negative (33). The fact that des-Arg Hb presents the same chromatographic behavior as acetylated $\mathrm{HbA}$ is consistent with the loss of the positively charged residues by des-Arg $\mathrm{Hb}$.

We determined the oxygen affinity of $\mathrm{HbA}$ and des-Arg $\mathrm{Hb}$ in the presence and in the absence of chloride ions (Figure 6). The lines through the experimental points represent the best non-linear fit of the parameters of the integrated Hill plot (which takes the functional form of the logistic equation) to the data. These parameters are shown

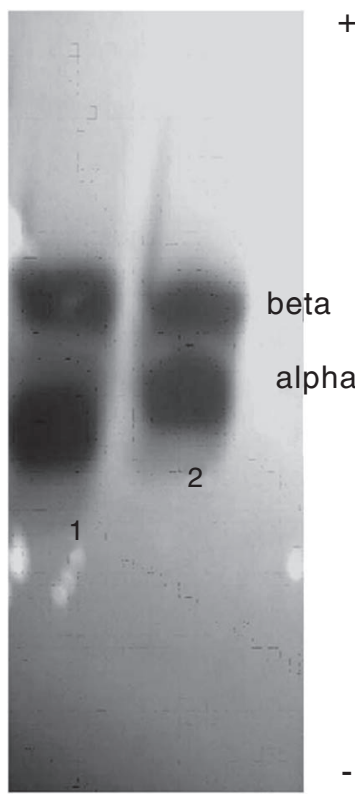

A

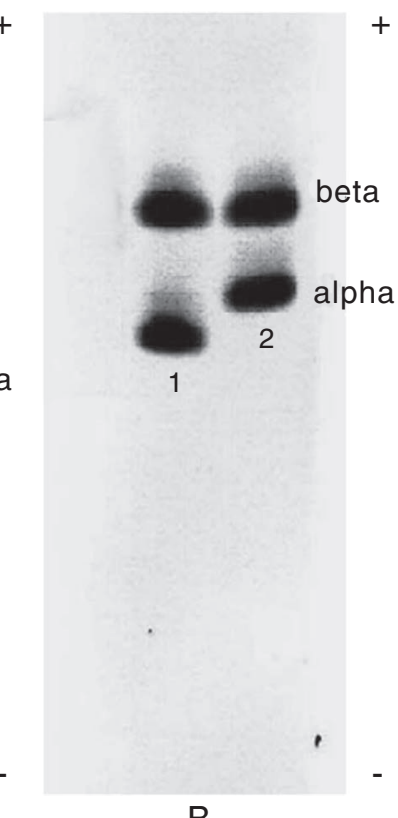

B

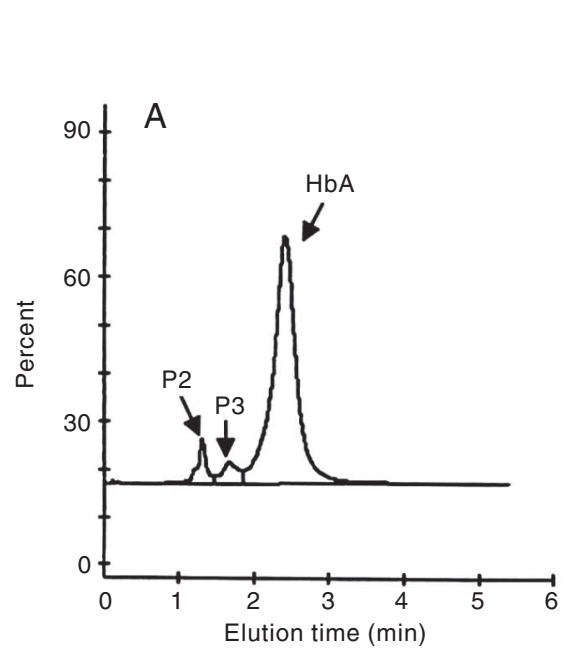

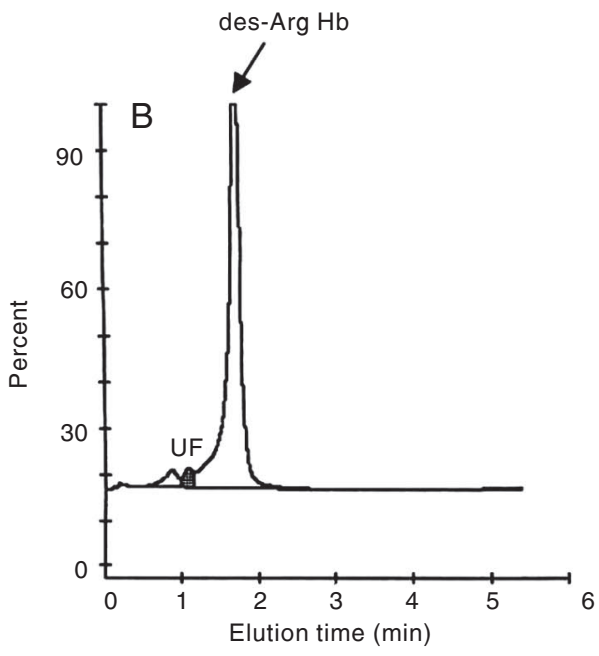

in Table 1.

The results show the different affinities for oxygen in each condition, represented by the sigmoidal adjustments of the curves. The oxygen binding curves are shifted to the left for des-Arg $\mathrm{Hb}$ in the absence and in the presence of chloride compared to the curves for $\mathrm{HbA}$ under the same conditions. This behavior shows that des-Arg $\mathrm{Hb}$ has a higher affinity for oxygen than $\mathrm{HbA}$ since the saturation of the protein requires a lower amount of oxygen than that needed for $\mathrm{HbA}$, in both cases. Therefore, a lower $\mathrm{p}_{50}$

Figure 4. Globin chain electrophoresis. Lane 1 indicates $\mathrm{HbA}$ and lane 2 indicates des-Arg $\mathrm{Hb}$. A, Tris-EDTA-boric acid (TEB) buffer, $\mathrm{pH} 5.0$, on $12 \%$ polyacrylamide gel with $5 \%$ acetic acid buffer. For each sample, $3 \mu \mathrm{L}$ of stock concentration of $11 \mathrm{mM} /$ heme for $\mathrm{HbA}$ and $7 \mathrm{mM} /$ heme for des-Arg $\mathrm{Hb}$ were applied. The gel was stained with Comassie blue for protein detection. $B$, TEB buffer, $\mathrm{pH}$ 8.6, in cellulose acetate. For each sample, $50 \mu \mathrm{L}$ of stock concentration of $11 \mathrm{mM} /$ heme for $\mathrm{HbA}$ and $7 \mathrm{mM} /$ heme for des-Arg $\mathrm{Hb}$ were applied. The gel was stained with amido black for protein detection. Both electrophoretic runs were carried out in the presence of $8 \mathrm{M}$ urea and $1 \mathrm{M}$ mercaptoethanol. The chains migrate from the negative (-) to the positive (+) pole. The $\beta$ chains of $\mathrm{HbA}$ and des-Arg $\mathrm{Hb}$ are identical; however, the $\alpha-$ chains present different patterns of migration, with des-Arg $\mathrm{Hb}$ being closer to the positive pole compared to the $\alpha$-chains of $\mathrm{HbA}$.

Figure 5. Cation exchange high-performance liquid chromatography of human $\mathrm{Hb}$ and the elution times ( $\mathrm{t}$. $A$, Chromatogram of $\mathrm{HbA}: \mathrm{t}$ $=2.4$. The glycosylated $(P 3): t=1.66$ and acetylated (P2): $t=1.3$ forms of $\mathrm{Hb}$ are also shown. $B$, Chromatogram of des-Arg $\mathrm{Hb}$, with the peak shifted to the acetylated fraction P3: $\mathrm{t}=$ 1.71. Also an unknown fraction $(\mathrm{U}): \mathrm{t}=0.88$, and fetal $(F): t=1.81 \mathrm{Hb}$ are present in small amounts. 


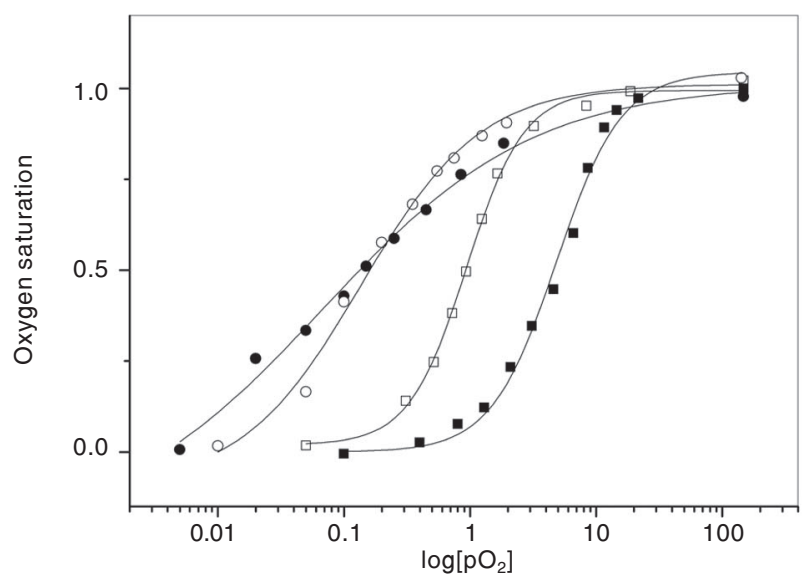

Figure 6. Oxygen binding curves of des-Arg $\mathrm{Hb}$ in $10 \mathrm{mM}$ HEPES-NaOH, pH 7.2, in the absence (open circles) and in the presence (filled circles) of $100 \mathrm{mM} \mathrm{NaCl}$. HbA in 10 mM HEPES$\mathrm{NaOH}, \mathrm{pH} 7.2$, in the absence (open squares), and in the presence (filled squares) of $100 \mathrm{mM} \mathrm{NaCl}$. All experiments were carried out with $\mathrm{Hb}$ concentration of $60 \mu \mathrm{M} / \mathrm{heme}$, at room temperature. All data curves were fitted with the best non-linear fit of the parameters of the integrated Hill plot, and the shift to the right of $\mathrm{HbA}$ (open and filled squares) indicates its lower affinity for oxygen compared to des-Arg $\mathrm{Hb}$.

Table 1. Oxygen affinities and cooperativities of $\mathrm{HbA}$ and desArg $\mathrm{Hb}$.

\begin{tabular}{lcc}
\hline & $\mathrm{HbA}$ & des-Arg Hb \\
\hline $\mathrm{p}_{50}(\mathrm{mmHg})$ & & \\
$\quad$ - chloride & $1.0 \pm 0.4$ & $0.17 \pm 0.01$ \\
+ chloride & $5.6 \pm 0.5$ & $0.14 \pm 0.01$ \\
$\mathrm{n}_{50}$ & & \\
- chloride & $2.2 \pm 0.20$ & $1.0 \pm 0.07$ \\
+ chloride & $2.3 \pm 0.20$ & $0.6 \pm 0.01$ \\
\hline
\end{tabular}

Data are reported as means $\pm S D$. $p_{50}=$ oxygen pressure at half saturation; $\mathrm{n}_{50}=$ Hill's coefficient indicating the cooperativity; $\mathrm{Hb}$ $=$ hemoglobin. The buffers used were $10 \mathrm{mM}$ HEPES in the absence or in the presence of $100 \mathrm{mM} \mathrm{NaCl}$, at pH 7.2 and $25^{\circ} \mathrm{C}$. The hemoglobin concentration was $60 \mu \mathrm{M} /$ heme.

\section{References}

1. Baldwin JM. Structure and function of haemoglobin. Prog Biophys Mol Biol 1975; 29: 225-320.

2. Baldwin JM. A model of co-operative oxygen binding to haemoglobin. Br Med Bull 1976; 32: 213-218.

3. Imai K. Allosteric effects in haemoglobin. Cambridge: Cambridge University Press; 1982.

4. Antonini E, Brunori M. Hemoglobin and myoglobin in their reactions with ligands. Amsterdam: Frontiers of Biology; 1971. value for des-Arg $\mathrm{Hb}$ in all cases compared to the value for $\mathrm{HbA}$ indicates its high affinity for oxygen, which was confirmed for different concentrations of chloride (Tosqui $P$, Colombo MF, unpublished results).

Table 1 shows the $p_{50}$ and the cooperativity $\left(n_{50}\right)$ values for both hemoglobins in the presence and in the absence of chloride. Both Hbs show a higher affinity for oxygen in the absence of chloride, in agreement with the fact that chloride stabilizes the deoxy state. However, when we consider only the curves for des-Arg $\mathrm{Hb}$, we notice that the results for the presence and absence of chloride are similar, a fact that could indicate the loss of chloride binding sites.

Taken together, the results show the characterization of des-Arg $\mathrm{Hb}$, and reflect the structural change in the functional behavior of this $\mathrm{Hb}$. The increased oxygen affinity is a consequence of the loss of stability of the deoxygenated quaternary structure, in which the arginines play an important role. Furthermore, this shift of the equilibrium for the oxygenated state, in the absence and presence of chloride, could act together with the loss of possible binding sites of this anion.

The physiological mechanism of this interaction has not been fully elucidated, but the biochemical analysis of des-Arg $\mathrm{Hb}$ can be used to identify a pattern of high-affinity hemoglobins in clinical studies.

\section{Acknowledgments}

We thank Dr. Marcelo Matos Santoro, Universidade Federal de Minas Gerais, for help with the mass spectrometry measurements. 
7. Kilmartin JV, Fogg JH, Perutz MF. Role of C-terminal histidine in the alkaline Bohr effect of human hemoglobin. Biochemistry 1980; 19: 3189-3193.

8. Perutz MF, Fermi G, Poyart C, Pagnier J, Kister J. A novel allosteric mechanism in haemoglobin. Structure of bovine deoxyhaemoglobin, absence of specific chloride-binding sites and origin of the chloride-linked Bohr effect in bovine and human haemoglobin. J Mol Biol 1993; 233: 536-545.

9. Fronticelli $\mathrm{C}$, Bucci $\mathrm{E}$, Orth $\mathrm{C}$. Solvent regulation of oxygen affinity in hemoglobin. Sensitivity of bovine hemoglobin to chloride ions. J Biol Chem 1984; 259: 10841-10844.

10. Fronticelli C, Sanna MT, Perez-Alvarado GC, Karavitis M, Lu AL, Brinigar WS. Allosteric modulation by tertiary structure in mammalian hemoglobins. Introduction of the functional characteristics of bovine hemoglobin into human hemoglobin by five amino acid substitutions. J Biol Chem 1995; 270: 30588-30592.

11. Marta M, Patamia M, Colella A, Sacchi S, Pomponi M, Kovacs KM, et al. Anionic binding site and 2,3-DPG effect in bovine hemoglobin. Biochemistry 1998; 37: 14024-14029.

12. Hui HL, Kavanaugh JS, Doyle ML, Wierzba A, Rogers PH, Arnone A, et al. Structural and functional properties of human hemoglobins reassembled after synthesis in Escherichia coli. Biochemistry 1999; 38: 1040-1049.

13. Fasan G, Grandgeorge M, Vigneron C, Dellacherie E. Preparation of unaltered hemoglobin from human placentas for possible use in blood substitutes. J Biochem Biophys Methods 1991; 23: 53-66.

14. Kilmartin JV, Rossi-Bernardi L. The binding of carbon dioxide by horse haemoglobin. Biochem J 1971; 124: 31-45.

15. Ikeda-Saito M. Studies on cobalt myoglobins and hemoglobins. The effect of the removal of the alpha-141 arginine residue on the functional and electronic properties of ironcobalt hybrid hemoglobins. J Biol Chem 1980; 255: 84978502.

16. Kavanaugh JS, Chafin DR, Arnone A, Mozzarelli A, Rivetti C, Rossi GL, et al. Structure and oxygen affinity of crystalline desArg141 alpha human hemoglobin A in the T state. $J$ Mol Biol 1995; 248: 136-150.

17. Michel B, Igic R, Leray V, Deddish PA, Erdos EG. Removal of Arg141 from the alpha chain of human hemoglobin by carboxypeptidases N and M. Circ Res 1996; 78: 635-642.

18. Antonini E, Wyman J, Zito R, Rossi-Fanelli A, Caputo A. Studies on carboxypeptidase digests of human hemoglobin. J Biol Chem 1961; 236: C60-C63.

19. Colombo MF, Bonilla-Rodriguez GO. The water effect on allosteric regulation of hemoglobin probed in water/glucose and water/glycine solutions. J Biol Chem 1996; 271: 4895-
4899.

20. Williams RC Jr, Tsay KY. A convenient chromatographic method for the preparation of human hemoglobin. Anal Biochem 1973; 54: 137-145.

21. Bonaventura J, Bonaventura C, Giardina B, Antonini E, Brunori M, Wyman J. Partial restoration of normal functional properties in carboxypeptidase A-digested hemoglobin. Proc Natl Acad Sci U S A 1972; 69: 2174-2178.

22. Kilmartin JV. Removal of specific $C$-terminal residues from human hemoglobin using carboxypeptidases A and B. Methods Enzymol 1981; 76: 167-171.

23. Joshi AA, McDonald MJ. Role of alpha and $\beta$ carboxylterminal residues in the kinetics of human oxyhemoglobin dimer assembly. J Biol Chem 1994; 269: 8549-8553.

24. Englander JJ, Louie G, McKinnie RE, Englander SW. Energetic components of the allosteric machinery in hemoglobin measured by hydrogen exchange. J Mol Biol 1998; 284: 1695-1706.

25. Folk JE, Piez KA, Carroll WR, Gladner JA. Carboxy-peptidase B. 4. Purification and characterization of the porcine enzyme. J Biol Chem 1960; 235: 2272-2277.

26. Wyman J Jr. Linked functions and reciprocal effects in hemoglobin: a second look. Adv Protein Chem 1964; 19: 223-286.

27. Bonini-Domingos CR. Metodologias laboratoriais para o diagnóstico de hemoglobinopatias e talassemias. 1st edn. São José do Rio Preto: Editora HN; 2006.

28. Schneider RG. Differentiation of electrophoretically similar hemoglobins - such as S, D, G, and P; or A2, C, E, and O by electrophoresis of the globin chains. Clin Chem 1974; 20: 1111-1115.

29. Alter BP, Goff SC, Efremov GD, Gravely ME, Huisman TH. Globin chain electrophoresis: a new approach to the determination of the G gamma/A gamma ratio in fetal haemoglobin and to studies of globin synthesis. Br J Haematol 1980; 44: 527-534.

30. Papadea C, Cate JC. Identification and quantification of hemoglobins $\mathrm{A}, \mathrm{F}, \mathrm{S}$, and $\mathrm{C}$ by automated chromatography. Clin Chem 1996; 42: 57-63.

31. Rossi-Fanelli A, Antonini E. Studies on the oxygen and carbon monoxide equilibria of human myoglobin. Arch Biochem Biophys 1958; 77: 478-492.

32. Benesch RE, Benesch R, Yung S. Equations for the spectrophotometric analysis of hemoglobin mixtures. Anal Biochem 1973; 55: 245-248.

33. Nathan DM, Francis TB, Palmer JL. Effect of aspirin on determinations of glycosylated hemoglobin. Clin Chem 1983; 29: 466-469. 